\title{
AEROBIC TRAINING COMBINED WITH NUTRITIONAL GUIDANCE AS AN EFFECTIVE STRATEGY FOR IMPROVING AEROBIC FITNESS AND REDUCING BMI IN INACTIVE ADULTS
}

\author{
Merete H. Helland, Gerd L. Nordbotten, \\ Cathrine N. Hagum, Leif I. Tjelta \\ Department of Education and Sports Science, University of Stavanger, Norway
}

\begin{abstract}
The aim of this study was to examine the impact of a 33-week program, which included two weekly intensive running sessions, on aerobic capacity, BMI, waist circumference and body composition in overweight and obese, inactive adults. An additional aim was to examine the additional impact of lifestyle modification education. Twenty-four participants in the Training Group (exercise only) and 27 in the Nutritional Guidance and Training Group (exercise + nutritional guidance) completed the study. Anthropometric measurements (BMI, waist circumference, visceral fat, muscle mass and fat percentage) and $3000 \mathrm{~m}$ running time were measured at start, after 15 weeks (BMI, waist circumference and $3000 \mathrm{~m}$ running time) and after 33 weeks of intervention. Significant reductions in BMI, waist circumference, fat percentage and $3000 \mathrm{~m}$ running time were found for both groups. A small, but insignificant, increase was found for muscle mass in both groups and visceral fat in the training group. A significant interaction effect for visceral fat was also found. Both groups improved their running time and anthropometric measurements. No significant differences were found between the groups.
\end{abstract}

Keywords: Interval training, overweight, waist circumference 


\section{INTRODUCTION}

Overweight, obesity and physical inactivity can lead to health problems, including hypertension, type 2 diabetes, cardiovascular diseases (CVD), stroke, colon cancer and breast cancer [38,44,52]. Physical activity (PA) gives positive health effects $[13,37,41,43,47]$ and there is dose-response relationship between PA and mortality in all age groups $[42,48]$. The Norwegian Directorate of health recommends a minimum of 150 minutes of moderateintensity PA weekly, alternatively 75 minutes of vigorous PA, or a combination of these. Only $31 \%$ of the adult population ( $>20$ years old) in Norway meet this requirement [16]. Inactive people are more often overweight and obese compared to physical active people [40].

Body mass index (BMI) and waist circumference (WC) are two commonly used parameters for defining general and abdominal obesity. In recent decades, BMI has increased in the population [24]. In the Norwegian adult population, $25 \%$ of men and $21 \%$ of women suffer from obesity $\left(\mathrm{BMI}>30 \mathrm{~kg} / \mathrm{m}^{2}\right)[20,36]$. There are also indications that abdominal obesity increases more than the increase in BMI can explain [10,20,36]. This can lead to an underestimation of the obesity-related health burden, when considering the observation that ectopic body fat (i.e. fat stored in the abdomen) is related to a range of metabolic abnormalities that are type 2 diabetes and CVD risk factors [18].

According to Luke and Cooper [32], PA has positive health-promoting benefits, but an increase in PA will not prevent weight gain for the majority of people and "only reduction in calorie intake will result in weight loss, whether done in isolation or together with increases in exercise". Blair et al. [1] criticized this assertion by referring to numerous studies showing that PA alone prevents weight gain. A study by Hankinson et al. [11] examined seven follow-up measurements over 20 years (3554 men and women) and concluded that those who maintained recommended levels of PA had smaller increases in BMI and WC compared to inactive men and women. Cross-sectional studies have also shown that a combination of low intensity activities (i.e. walking) and high intensity activities is optimal for weight control [35] and prevention of CVD [34]. Moreover, individuals who spend around $30 \%$ of their PA time engaged in vigorous activities such as running were most successful in maintaining body weight over time [26]. According to a review published by Clark [5] that examined weight-loss and changes in fitness for obese adults aged 18-65 years, reduced energy diet and exercise were found to be more efficient than diet or exercise alone. Regardless of general and abdominal adiposity, inactive and moderately active groups 
reduce all-cause mortality when starting PA $[8,36]$. Regular PA is also associated with a lower risk of death regardless of BMI [31]. Lavie [29] describes the "the obesity paradox", indicating that fit, obese people have reduced CVD risk compared to unfit, slim people, and that greater emphasis should be placed on improving fitness rather than just focusing on weight. Even without significant weight loss, significant health benefits can be achieved $[2,3,12,25,40,49]$.

The objectives of the present study were to: 1) examine the impact of a 33-week program that included two weekly intensive running sessions on aerobic capacity and anthropometric measurements in overweight and obese adults, 2) examine if there were any additional effects of lifestyle modification education on aerobic capacity and anthropometric measurements.

\section{MATERIAL AND METHODS}

\section{Design}

The present study was initiated by the University of Stavanger in cooperation with the largest newspaper in the southwest region of Norway. Participants were recruited from the newspapers readers. A total number of 72 participants ( 49 women) with a mean age of $46.1( \pm 10.4)$ years were included after meeting the inclusion criteria: previously untrained and inactive adults in all age groups, BMI $\geq 25 \mathrm{~kg} / \mathrm{m}^{2}$, desire to become fitter and reduce BMI. Participants were randomized, using Research Randomizer, into a Training Group (TG) ( $n=40)$ or a Nutritional guidance and Training Group (NTG) $(n=32)$. All participants followed a training program with two weekly, supervised training sessions consisting of interval running/walking and ending with general strength training. In addition, participants were encouraged to do two weekly alternative training sessions at moderate intensity of minimum 30 min each (e.g. resistance training, walking, swimming, spinning, aerobics). Activity and duration were reported in training diaries. In addition to training, the NTG also received nutritional guidance and practical cooking lessons. In total 51 participants completed the study, 24 (17 women) in the TG and 27 (17 women) in the NTG. The most important reasons for drop-out were health problems not directly related to the intervention. All participants provided signed, written, informed consent. The Regional Committees for Medical and Health Research Ethics in Norway approved the study. Characteristics for the participants at start of the intervention are presented in Table 1. 
Table 1. Characteristics for the participants at start of the intervention (T1). Data presented as Mean \pm SD.

\begin{tabular}{lccc}
\hline Measure & $\begin{array}{c}\text { Total } \\
(\mathbf{n}=74)\end{array}$ & $\begin{array}{c}\text { NTG } \\
(\mathbf{n}=34)\end{array}$ & $\begin{array}{c}\text { TG } \\
(\mathbf{n}=40)\end{array}$ \\
\hline Age (year) & $46.1 \pm 10.4$ & $47.8 \pm 9.1$ & $44.6 \pm 11.2$ \\
\hline Body weight $(\mathrm{kg})$ & $97.1 \pm 14.7$ & $98.1 \pm 14.0$ & $96.3 \pm 15.5$ \\
\hline High $(\mathrm{cm})$ & $171.0 \pm 8.9$ & $171.6 \pm 9.0$ & $170.6 \pm 8.9$ \\
\hline BMl $\left(\mathrm{kg} / \mathrm{m}^{2}\right)$ & $33.1 \pm 3.9$ & $33.8 \pm 3.9$ & $33.0 \pm 3.9$ \\
\hline WC $(\mathrm{cm})$ & $108.7 \pm 14.6$ & $110.2 \pm 17.5$ & $107.5 \pm 11.7$ \\
\hline Fat per cent $(\%)$ & $39.95 \pm 6.74$ & $40.20 \pm 6.64$ & $39.72 \pm 6.92$ \\
\hline Muscle mass $(\mathrm{kg})$ & $32.80 \pm 6.91$ & $32.97 \pm 7.14$ & $32.66 \pm 6.78$ \\
\hline Visceral fat $\left(\mathrm{cm}^{2}\right)$ & $149.06 \pm 45.83$ & $157.15 \pm 43.18$ & $141.83 \pm 47.48$ \\
\hline
\end{tabular}

SD - standard devaitaion; BMI - Body mass index; WC - Waist circumference; NTG - Nutritional Guidance and Training Group; TG - Training Group.

\section{Training and nutritional guidance}

In this study, participants from the TG maintained their usual diet and were offered education in theoretical and practical themes after the intervention. Participants in NTG received nutritional guidance but were not committed to following a specific diet. They received group lessons concerning different theoretical themes and practical cooking (Table 2). Both theoretical and practical nutritional guidance were based on recommendations from the Norwegian Directorate of Health $[14,15]$. The Norwegian Directorate of Health recommends that 10 to $20 \%$ of total calories should be from protein, 45 to $60 \%$ from carbohydrate ( $\max 10 \%$ from sugar) and 25 to $40 \%$ from fat (with maximum 10\% from saturated fat). Participants in NTG were recommended to reduce their energy consumption to $1500-1700 \mathrm{kcal} /$ day. Recommendations from The Norwegian Directorate of Health [15] emphasize intake of large quantities of high-bulk, low energy-density foods (like vegetables, fruits and high-fiber grains) and moderation in the consumption of high energy-density foods (like meat, cheese, sugar and fat). During the project-period, NTG attended ten 80 -min theoretical sessions and eight 140-min practical cooking sessions. In between group education NTG used Facebook as a communication channel. Establishing a group for invitees only made it possible to ask questions and publish relevant information. All recipes and theoretical presentations were available at this site. 
Table 2. Education themes in the lifestyle intervention program.

\begin{tabular}{|c|c|}
\hline $\begin{array}{l}\text { Week number } \\
\text { during the } \\
\text { program: }\end{array}$ & $\begin{array}{l}\text { Education concerning: } \\
1=\text { theoretical theme, } 2=\text { practical cooking }\end{array}$ \\
\hline 1 & 1 (Introduction to nutrition and training) \\
\hline 3 & 1 (Nutrition/training) \\
\hline 4 & 2 (Breakfast) \\
\hline 6 & 2 (Soups) \\
\hline 8 & 1 (Nutrition/training) \\
\hline 9 & 1 (Nutrition/training) \\
\hline 10 & 2 (Calories and Temptations) \\
\hline 15 & 1 (Cognitive therapy) \\
\hline 16 & 2 (Alternative snack) \\
\hline 18 & 1 (Cognitive therapy) \\
\hline 19 & 2 (Chicken and fish I) \\
\hline 21 & 1 (Nutrition/training) \\
\hline 23 & 1 (Nutrition/Cognitive therapy) \\
\hline 24 & 2 (Chicken and fish II) \\
\hline 26 & 2 (legumes) \\
\hline 30 & 2 (Simple, healthy dishes) \\
\hline 32 & 1 (Nutrition) \\
\hline 33 & 1 (How to sustain the new lifestyle) \\
\hline
\end{tabular}

\section{Supervised interval running and strength training sessions}

The two weekly, supervised training sessions consisted of 10-min warm up followed by 20-21-min effective interval running (or fast walking for the most unfit). Typical sessions were: 1) $8 \times 3$ min running, with one-minute walking recovery. 2) $20 \times 1$ min running with $30 \mathrm{sec}$ walking recovery. 3) $6 \mathrm{~min}, 5 \mathrm{~min}, 4 \mathrm{~min}, 3 \mathrm{~min}, 2 \mathrm{~min}$ and $1 \mathrm{~min}$ running with one-minute walking recovery. The aim was that running should be performed with a heart rate of $85-90 \%$ of maximum heart rate. Sessions were concluded with ten minutes of whole body strength training consisting of 15-20 chest flies, $2 \times 10$ walking lunges, $2 \times 10$ squats, $2 \times 10$ push-ups, and exercises for back and stomach muscles. 


\section{Tests}

Measurements of BMI, WC and 3000 m running time were performed at the start of the project (Time 1 (T1)), after 15 weeks (T2) and at the end of the project (T3). Measurements of fat percentage, muscle mass and visceral fat were performed at T1 and at T3. Twelve participants ( 9 women) from both groups (TG=7 and $\mathrm{NTG}=5$ ), performing around average in $3000 \mathrm{~m}$ running test at $\mathrm{T} 1$ also did a $\mathrm{VO}_{2 \max }$ test at $\mathrm{T} 1$ and $\mathrm{T} 3$.

\section{0 m running test}

All participants ran $3000 \mathrm{~m}$ test around a local lake. The surface is firm cinder and the difference between highest and lowest points is less than 3 meters. To become familiar with the test distance, the participants ran a pilot test round the lake one week before T1.

\section{$\mathrm{VO}_{2 \max }$ test}

The test was performed as a modified Balke test [7]. Woodway treadmill (Woodway, ELG 2, Weil am Rhein, Germany) was used as ergometer. The test person (TP) was connected to the analyzer (Vintus CPX CareFusion, USA), which was calibrated with room air and certified calibration gases before each test. The test started with a four min warm up on the treadmill at a pace of $4.8 \mathrm{~km} / \mathrm{h}$ with a $4 \%$ incline, and then the incline increased every minute by $2 \%$ until a maximum incline of $20 \%$ was reached. If TP was able to continue, the speed was increased by $0.5 \mathrm{~km} / \mathrm{h}$ per min until the TP reached exhaustion. Borg's Rating of Perceived Exertion [4] was used to register exertion at the end of the test. Exhaustion criteria were Borg Rating $\geq 15$ and $\mathrm{R}$-value $\geq 1$.1. Polar Sport tester (Polar Electro Oy, Kempele, Finland) registered heart rate (HR). The highest $\mathrm{HR}$ during the test was defined as $\mathrm{HR}_{\max }$.

\section{Anthropometric measurements}

Height and weight were measured with participants lightly clothed and without shoes. BMI and WC were measured at T1, T2 and T3. The participants were in standing position during all body measurements. A calibrated digital scale (Seca, model 770, Seca Corp, Hamburg, Germany) was used for the body weight measure. Waist circumference was measured from the point midway between the inferior margin of the last rib and the crest of the ilium. InBody 720 (Biospace Co., Ldt, Seoul, Korea) was used for the measure of body fat percentage, muscle mass and visceral fat at $\mathrm{T} 1$ and $\mathrm{T} 3$. 


\section{Training registration}

Self-recall training diaries are a frequently used tool to quantify training load and training information. Type and duration of all training sessions were reported. Participants who followed $\geq 75 \%$ of the supervised interval training sessions and in addition reported minimum two individual sessions per week, including alternative sessions, were included in the study.

\section{Registration of training intensity}

In order to describe the intensity during the interval training sessions HR was registered by Polar Sport tester during four weeks (eight interval sessions) for the 12 participants who performed the $\mathrm{VO}_{2 \max }$ tests at $\mathrm{T} 1$.

\section{Statistical Analyses}

Mixed design with two-way multivariate analysis of variance (MANOVA) was conducted to assess the effectiveness of the intervention. In this design, the effect of two factors (between-subjects and within-subjects) on a group of dependent variables was investigated simultaneously. This makes it possible to investigate the multivariate as well as the univariate effects of withinsubjects and between-subjects factors along with the interaction between them on a group of dependent variables [46]. The analysis was done in two phases. First, the effects of independent variables were examined on the combined group of dependent variables. Second, the effects of independent variables were investigated in each of the dependent variable separately [46].

The dependent variables in this study were BMI, fat percentage, muscle mass, running time, visceral fat and WC, with Time (T1, T2 and T3) as the within-subjects variable, and Group (TG and NTG) as between-subjects variable. Two different two-way MANOVAs were conducted. For the first MANOVA, Time had three levels: pre-test (T1), test after 15 weeks (T2) and post-test after 33 weeks (T3). Group had two levels (TG and NTG), and the dependent variables were BMI, running time and WC. For the second MANOVA, Time had two levels (T1 and T3), Group had two levels (TG and NTG), and the dependent variables were fat percentage, muscle mass and visceral fat. If the multivariate interaction was non-significant, the multivariate main effects of the between-subjects and within-subjects variables on the group of dependent variables were investigated.

The relationship between $\mathrm{VO}_{2 \max }$ and $3000 \mathrm{~m}$ running test at $\mathrm{T} 3$ was determined using Pearson product-moment correlation coefficient. A paired samples t-test was conducted to evaluate the impact of the intervention on participants' scores on $3000 \mathrm{~m}$ running time from T1 to T3. 
Preliminary analysis was performed to ensure no violation of the assumptions of normality, linearity and homoscedasticity. Values for skewness and kurtosis were between \pm 2 (kurtosis for running time was \pm 4 ), indicating a normal univariate distribution. Data are presented as mean $(\mathrm{M}) \pm$ standard deviation of the mean (SD). The alpha level for significance was set to $\mathrm{p}<0.05$. For pairwise comparisons, Bonferroni correction was applied for correcting the level of significance $(0.05 / 3=0.017)$. Effect size was calculated with Partial Eta Squared $\left(\eta^{2}\right)$ statistic and was defined as small (0.01), medium (0.06), or large ( $>0.138)$ [6]. All analyses were performed using IBM SPSS Statistics Version 25.0.

\section{RESULTS}

\section{$\mathrm{BMI}, \mathbf{3 0 0 0} \mathrm{m}$ running time and WC}

The multivariate effect of Group (TG and NTG) on the combined dependent variables of Time (T1, T2 and T3) was statistically non-significant irrespective of Group. However, there was a significant multivariate effect of Time in the combined dependent variables irrespective of Group: Wilks $\lambda=0.376$, $F(6,34)=9.39 ; p<0.001$ and partial $\eta^{2}=0.62$. This indicates a very large effect size. There was a non-significant multivariate effect across the interaction between Group $x$ Time: Wilks $\lambda=0.780, F(6,34)=1.60 ; \mathrm{p}=0.177$ and partial $\eta^{2}=0.22$, indicating a large effect size.

The main effect of Group was statistically non-significant $(p>0.017)$ on any of the Group characteristics, that is, TG and NTG irrespective of the dependent variables. The main effect of Time was significant irrespective of the Groups for BMI: $F(1,64)=16.92 ; p<0.001$, running time: $F(1,67)=34.27$; $\mathrm{p}<0.001$, and WC: $\mathrm{F}(1,71)=19.67 ; \mathrm{p}<0.001$. Partial $\eta^{2}$ were $0.30,0.47$ and 0.34 , respectively, indicating large effect sizes. The interaction effect of Time $\times$ Group was non-significant in any of the dependent variables. Figures 1, 2 and 3 show estimated marginal mean plots for BMI, 3000m running time and $\mathrm{WC}$ respectively at $\mathrm{T} 1, \mathrm{~T} 2$ and $\mathrm{T} 3$ for both groups. 


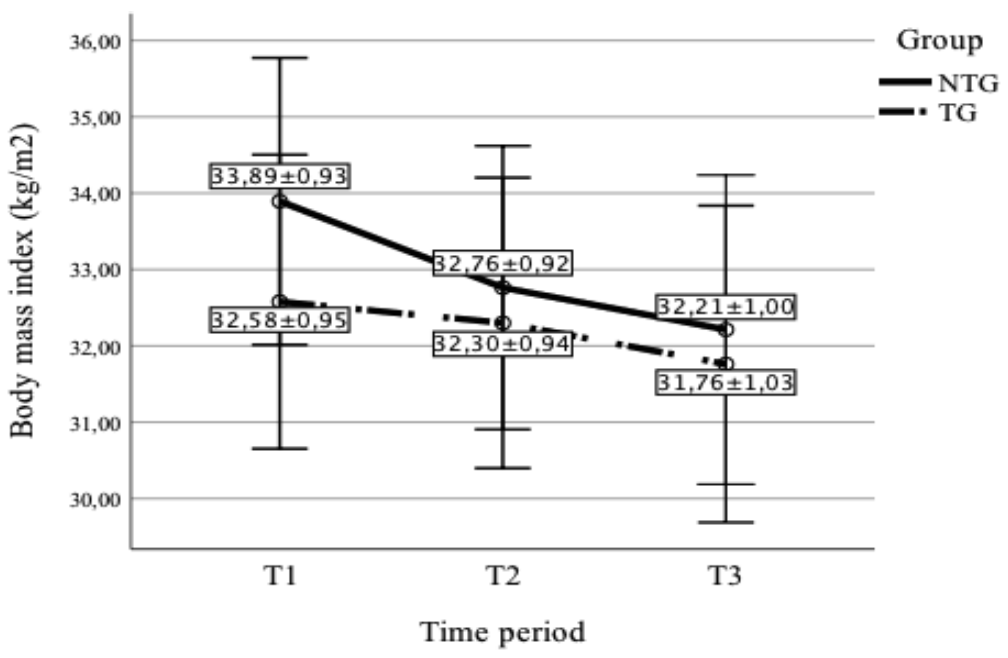

Figure 1. Estimated marginal means plot at $\mathrm{T} 1, \mathrm{~T} 2$ and $\mathrm{T} 3$ for data on $\mathrm{BMI}$ for both groups. Data are presented as $\mathrm{M} \pm \mathrm{SD}$. Error bars $95 \% \mathrm{Cl}$.

Figure 1 shows that BMI decreased from T1 to T3 ( $\mathrm{p}<0.017)$. Analysing data by combining both groups, the difference between $\mathrm{T} 1$ and $\mathrm{T} 2$ is statistically significant $(\mathrm{p}<0.017)$, whereas the difference between $\mathrm{T} 2$ and T3 is nonstatistical significant $(\mathrm{p}>0.017)$.

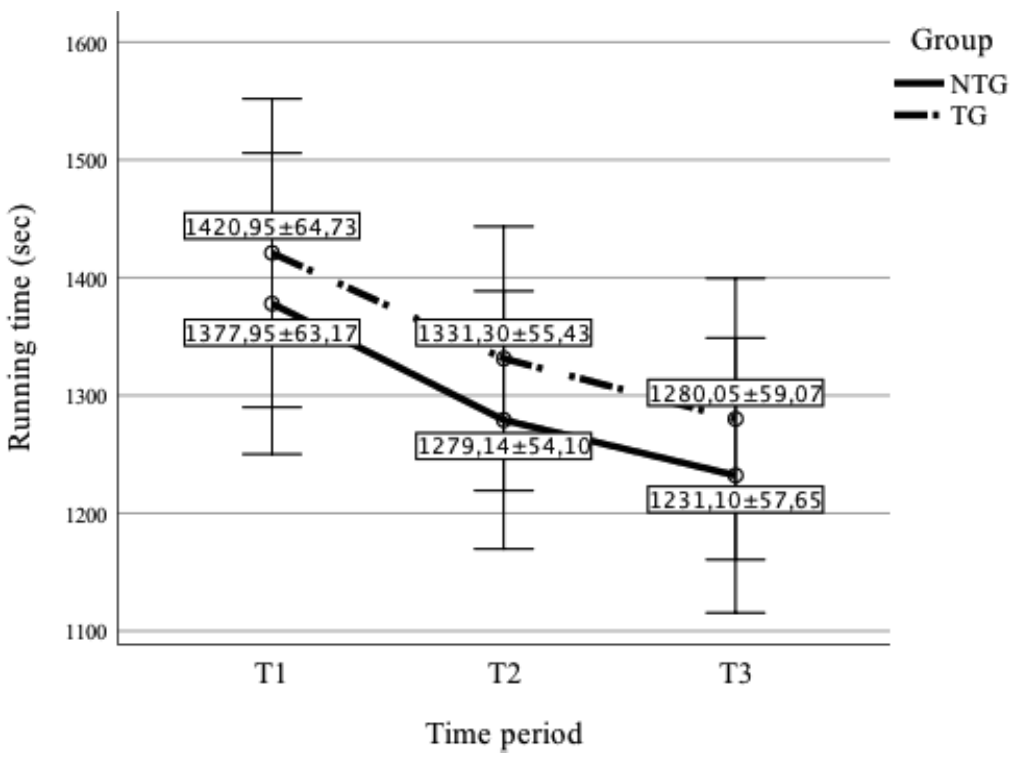

Figure 2. Estimated marginal means plot at $\mathrm{T} 1, \mathrm{~T} 2$ and $\mathrm{T} 3$ for data on running time for both groups. Data are presented as $\mathrm{M} \pm \mathrm{SD}$. Error bars $95 \% \mathrm{Cl}$. 
Figure 2 shows that running time decreased from $\mathrm{T} 1$ to $\mathrm{T} 3$, from $\mathrm{T} 1$ to $\mathrm{T} 2$, as well as from T2 to T3 (both groups combined). The difference between all times is statistically significant $(\mathrm{p}<0.017)$. For all participants the mean decrease in running time was $145 \mathrm{sec}( \pm 129 \mathrm{sec})$ with a $95 \%$ confidence interval ranging from 106 to 184 . The eta squared statistic (0.56) indicates a large effect size.

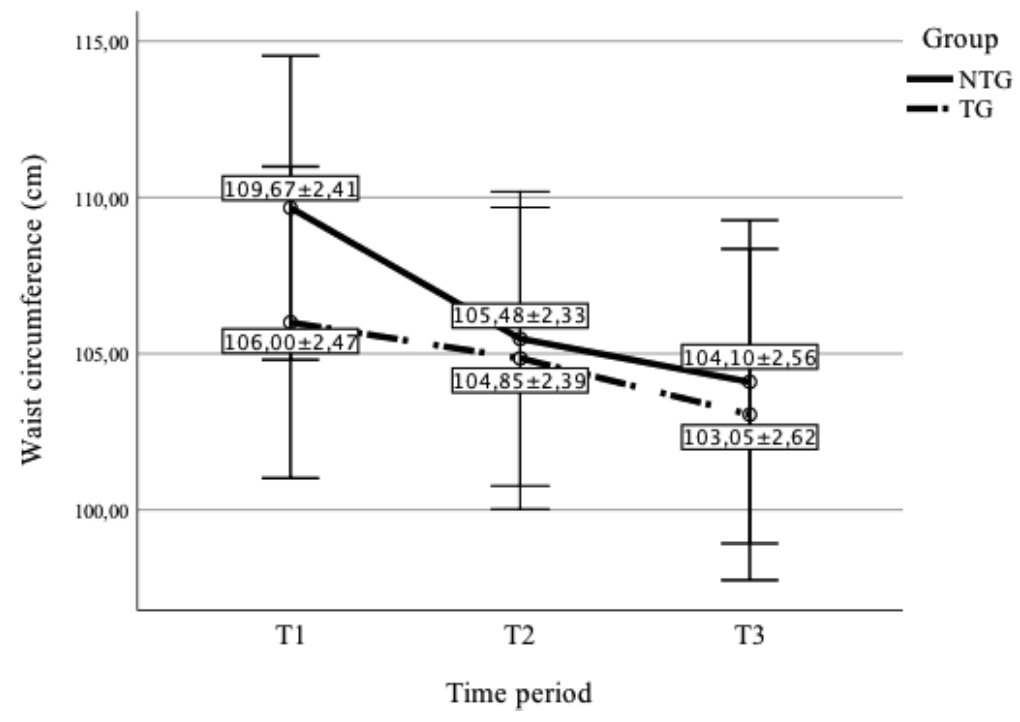

Figure 3. Estimated marginal means plot at $\mathrm{T} 1, \mathrm{~T} 2$ and $\mathrm{T} 3$ for data on WC for both groups. Data are presented as $\mathrm{M} \pm \mathrm{SD}$. Error bars $95 \% \mathrm{Cl}$.

In figure 3, WC decreased from $\mathrm{T} 1$ to $\mathrm{T} 3(\mathrm{p}<0.017)$. The difference between $\mathrm{T} 1$ and $\mathrm{T} 2$ is statistically significant $(\mathrm{p}<0.017)$, whereas the difference between T2 and T3 is statistically non-significant (both groups combined).

\section{Fat percentage, muscle mass and visceral fat}

The multivariate effect of Group on the combined dependent variables of Time was statistically non-significant irrespective of Group. However, there was a significant multivariate effect of Time in the combined dependent variables irrespective of Group: Wilks $\lambda=0.548, F(3,40)=11.00 ; \mathrm{p}<0.001$ and partial $\eta^{2}=0.45$. This indicates a large effect size. There was a non-significant multivariate effect across the interaction between Time and Group: Wilks $\lambda=0.857, \mathrm{~F}(3,40)=2.23 ; \mathrm{p}=0.099$ and partial $\eta^{2}=0.14$, which indicates a large effect size. 
Since sphericity assumption was not violated for the data on any of the three dependent variables for comparing performance across Time $\times$ Group, no correction was applied. The main effect of Group was statistically nonsignificant $(\mathrm{p}>0.05)$. The main effect of Time was significant irrespective of Group only for fat percentage: $F(1,42)=28.53$; $p<0.001$ and partial $\eta^{2}=0.41$, which indicates a very large effect size. The interaction effect of Time $\times$ Group was statistically significant only for visceral fat: $F(1,42)=4.19$; $p=0.047$ and partial $\eta^{2}=0.09$, indicating moderate to high effect size.

Table 3 gives descriptive statistics for each test for both Groups, while table 4 shows pairwise comparisons based on descriptive statistics. Estimated marginal means of Time $\mathrm{x}$ Group for data on visceral fat are shown in Figure 4.

Table 3. Descriptive statistics, Marginal means for each test for both Groups.

\begin{tabular}{lccc}
\hline Measure & Group & $\mathrm{M} \pm \mathrm{SD}$ & $95 \% \mathrm{Cl}$ \\
\hline \multirow{2}{*}{ Fat percentage } & TG $(\mathrm{n}=20)$ & $39.29 \pm 1.57$ & $36.12-42.46$ \\
\cline { 2 - 4 } & $\mathrm{NTG}(\mathrm{n}=24)$ & $39.38 \pm 1.43$ & $36.48-42.27$ \\
\hline \multirow{2}{*}{ Muscle mass } & TG $(\mathrm{n}=20)$ & $31.87 \pm 1.44$ & $28.97-34.78$ \\
\cline { 2 - 4 } & NTG $(\mathrm{n}=24)$ & $32.72 \pm 1.31$ & $30.07-35.37$ \\
\hline \multirow{2}{*}{ Visceral fat } & TG $(\mathrm{n}=20)$ & $142.95 \pm 8.98$ & $124.83-161.07$ \\
\cline { 2 - 4 } & NTG $(\mathrm{n}=24)$ & $146.28 \pm 8.20$ & $129.74-162.81$ \\
\hline
\end{tabular}

Table 4. Pairwise comparisons based on estimated marginal means.

\begin{tabular}{lccccc} 
Measure & Time (I) & Time $(\mathrm{J})$ & $\begin{array}{c}\text { Mean Difference }(\mathrm{I}-\mathrm{J}) \\
\pm \mathrm{SD}\end{array}$ & Sig. $^{\mathrm{b}}$ & $95 \% \mathrm{Cl}^{\mathrm{b}}$ \\
\hline Fat percentage & 1 & 3 & $2.50 \pm 0.47^{*}$ & $<0.001$ & $1.55-3.44$ \\
\hline Muscle mass & 1 & 3 & $-0.13 \pm 0.12$ & 0.299 & $-0.37-0.12$ \\
\hline Visceral fat & 1 & 3 & $7.54 \pm 6.22$ & 0.232 & $-5.02-20.09$ \\
\hline
\end{tabular}

Based on estimated marginal means

I - Time 1 (pretest); J - Time 3 (posttest); $\mathrm{Cl}$ - Confidence intervals.

* The mean difference is significant at the $p<0.05$

${ }^{\mathrm{b}}$ Adjustment for multiple comparisons by Bonferroni

Visceral fat measurement in NTG decreased from T1 to T3, while it increased in TG from T1 to T3 (Figure 4). 


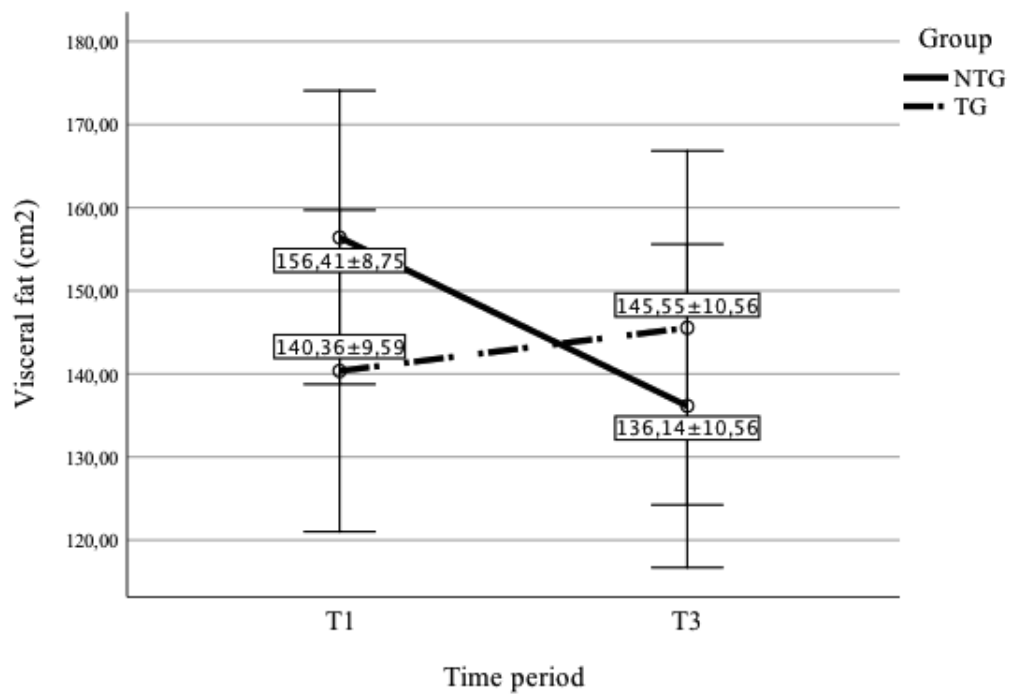

Figure 4. Estimated marginal means plot at $\mathrm{T} 1$ and $\mathrm{T} 3$ for data on visceral fat for both groups. Data are presented as $\mathrm{M} \pm \mathrm{SD}$. Error bars $95 \% \mathrm{Cl}$.

$\mathrm{VO}_{2 \max }$

The 12 participants who tested $\mathrm{VO}_{2 \max }$ had an increase of $2.86( \pm 3.84) \mathrm{ml} /$ $\mathrm{kg} / \mathrm{min}$ in $\mathrm{VO}_{2 \max }$ from $\mathrm{T} 1$ to $\mathrm{T} 3$, from $29.21( \pm 2.95)$ to $32.07( \pm 6.16) \mathrm{ml} /$ $\mathrm{kg} / \mathrm{min}$. Their average reduction in $3000 \mathrm{~m}$ running time from $\mathrm{T} 1$ to $\mathrm{T} 3 \mathrm{was}$ $181 \mathrm{sec}( \pm 121 \mathrm{sec})$, from $1405 \mathrm{sec}( \pm 91 \mathrm{sec})$ to $1224 \mathrm{sec}( \pm 149 \mathrm{sec})$. Figure 5 shows the relationship between $\mathrm{T} 3 \mathrm{VO}_{2 \max }$ and $\mathrm{T} 33000 \mathrm{~m}$ running time for 12 participants. There was a strong, negative correlation between the two variables, $\mathrm{r}=-0.89, \mathrm{n}=12, \mathrm{p}<0.001$.

\section{Heart rate during the interval running sessions}

The 12 participants who measured HR during eight interval sessions had a HR from 85 to $92 \%$ of $\mathrm{HR}_{\max }$ when running the intervals. The HR dropped to $70-75 \%$ of $\mathrm{HR}_{\max }$ during the recovery periods. 


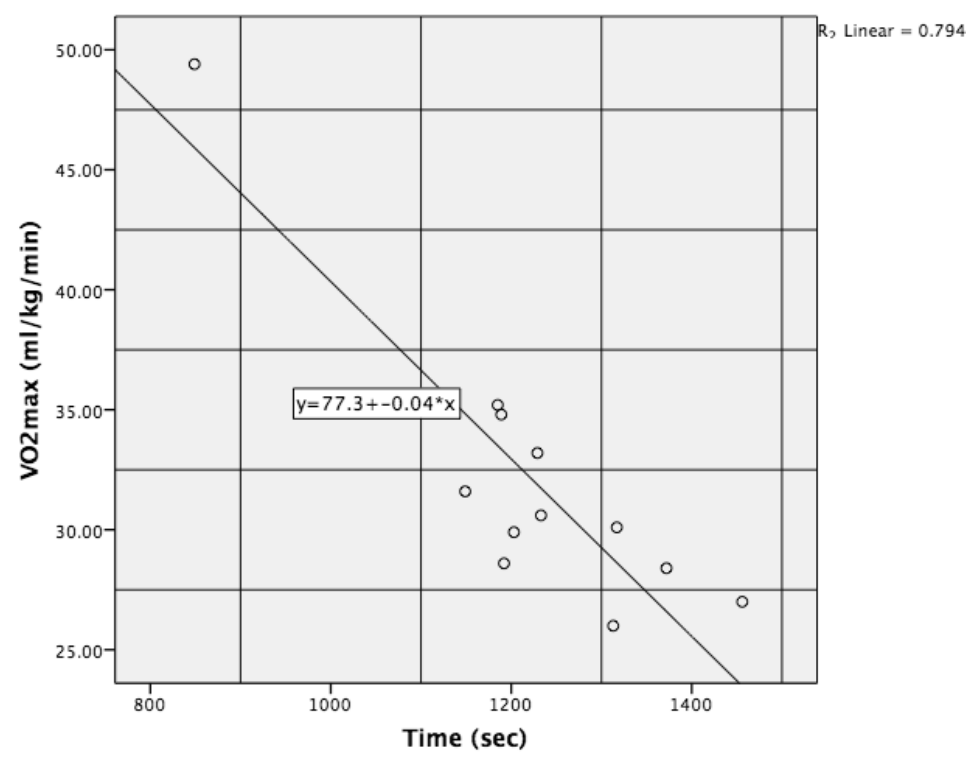

Figure 5. Relationship between post-test $\mathrm{VO}_{2 \max }$ and post-test running time over $3000 \mathrm{~m}$ $(n=12)$.

\section{DISCUSSION}

\section{Changes in aerobic capacity}

The best predictor of aerobic fitness is proven to be $\mathrm{VO}_{2 \max }$ [39]. An increase in $\mathrm{VO}_{2 \max }$ of $3.5 \mathrm{ml} / \mathrm{kg} / \mathrm{min}$ is associated with a $13 \%$ reduction in all-cause mortality [27]. The present study shows an average improvement in $\mathrm{VO}_{2 \max }$ of $2.9 \mathrm{ml} / \mathrm{kg} / \mathrm{min}(9.2 \%)$ and average improvement in $3000 \mathrm{~m}$ running time (for the twelve average participants) of $186 \mathrm{sec}$ (12.9\%), which can be reflected in their weight loss. The three subjects with the highest amount of reported total training sessions had an average increase in $\mathrm{VO}_{2 \max }$ of $7.4 \mathrm{ml} / \mathrm{kg} / \mathrm{min}(22.1 \%)$, which is associated with large health benefits. Two of these participants were in the NTG and one was in the TG. The two participants in NTG had a weight reduction of 9.8 and $19.6 \%$, and the participant in TG had $2.0 \%$ reduction in weight.

As shown in Figure 5, there is a strong negative correlation between running time and $\mathrm{VO}_{2 \max }$. Running time for $3000 \mathrm{~m}$ can therefore be used to estimate $\mathrm{VO}_{2 \max }$. No multivariate effect was found between groups with regards to running time, but for pairwise comparisons based on estimated means we found a significant reduction between $\mathrm{T} 1$ and $\mathrm{T} 2$, as well as between $\mathrm{T} 2$ and T3 ( $\mathrm{p}<0.017)$. Results describe a continuous improvement in running time throughout the intervention period. The HR during the interval sessions 
was between 85 and $92 \%$ of $\mathrm{VO}_{2 \max }$. During warm up and recovery, the $\mathrm{HR}$ never fell below $70 \%$ of $\mathrm{HR}_{\max }$. None of the studies as Verheggen et al. [45] have referred to have been performed with such high intensity. In contrast to previous studies, participants in the present study achieved a significant decrease in weight and significant reduction in WC. High intensity exercise, which entails greater post-exercise energy consumption, can be an explanation. In a systematic review and meta-analysis consisting of 13 articles, Wewege et al. [50] compared the effects of high-intensity interval training and moderate-intensity continuous training on body composition in overweight and obese adults. They found no difference between the groups based on intensity but running resulted in a significant effect on body composition while cycling did not. The use of high-intensity interval running is characteristic for the present study and findings indicate that this type of training has positive effects on body composition in overweight and obese adults.

\section{Changes in BMI}

Core intervention targets for the NTG were to establish regular eating patterns, focusing on eating breakfast, reducing portion size (and plate size) and replacing high calorie beverages with water. Participants were advised to use an online calorie counter (MyFitnessPal/Lifesum) and special attention was given to continuous registration of energy intake and expenditure.

The use of social media in intervention projects has helped individuals lose weight [21]. In this intervention, Facebook was used in combination with classroom lessons. The NTG experienced a mean weight loss of $3.8 \%$ of initial body weight, $1.7 \%$ greater than the TG (non-significant). Despite the fact that we found no significant differences between the TG and the NTG in the present study, obtained results may give successful practical outcomes. For example, a 5\% reduction in total body weight can provide clinically significant changes to CVD factors [9] and it is likely that even a smaller reduction will give some benefits. A lower BMI is associated with a lower cancer mortality risk and even short-term changes in BMI are associated with lower mortality from any type of cancer [43]. Although no significant differences were found between the groups, BMI was significantly reduced from T1 to $\mathrm{T} 2(\mathrm{p}<0.017)$ for both groups. No significant reduction was found from T2 to T3, indicating that major weight loss does occur during the first weeks of PA, which was also confirmed by Lv et al. [33]. Results indicate that major reductions in BMI are due to exercise and only minor changes by nutritional guidance. However, another explanation of the lack of significant differences might be an increased interest in food and nutrition by both groups, because of an overall increased focus on exercise and health. 


\section{Changes in WC}

Lean et al. [30] proposed that WC values should be classified into three risk strata $(<94,94-102$, and $>102 \mathrm{~cm}$ in men; $<80,80-88$, and $>88 \mathrm{~cm}$ in women) and that men with WC $\geq 102 \mathrm{~cm}$ and women with $\mathrm{WC} \geq 88 \mathrm{~cm}$ should reduce their weight. All participants had a WC above these limits when starting the intervention. Six participants reduced their WC to below these limits during the intervention period (one woman and three men in the NTG, one woman and one man in the TG). No multivariate effect was found for BMI and WC and pairwise comparisons are based on estimated means, which showed a significant reduction of both WC and BMI from T1 to T2 $(\mathrm{p}<0.017)$. No further reduction from T2 to T3 ( $>>0.017)$ was found. Although non-significant, NTG reduced their WC more than the TG. Reduction in WC for the NTG was 5.1\%, which is almost twice as much as for the TG, which had a reduction of $2.8 \%$. For both groups, the percentage reduction in WC is similar to the reduction in BMI (NTG 5\%, TG 2.5\%). The World Health Organization $[51,53]$ recognizes that WC between $94.0-$ $101.9 \mathrm{~cm}$ in men and $80.0-87.9 \mathrm{~cm}$ in women correspond to the BMI overweight range of $25-29.9 \mathrm{~kg} / \mathrm{m}^{2}$. According to Janssen et al. [23], WC, more than BMI, explains obesity-related health risks. Thus, for a given WC value, overweight, obese and normal weight individuals have comparable health risks. For a given health benefit, it would therefore be favourable if WC was reduced to a greater extent than the reduction in BMI, although results from the present study indicate a correspondence between BMI and WC.

\section{Fat percentage, muscle mass and visceral fat}

Examination of mean scores for each test and time period and pairwise comparisons of these estimated marginal means, show that there is a significant difference in fat percentage during the intervention period (T1 to T3) $(\mathrm{p}<0.05)$. Results indicate that measurements for fat percentage in both groups decreased from T1 to T3, and small, but insignificant, increase in muscle mass was observed for both groups ( $p>0.05)$. Strength training is important for maintaining muscle mass [5] and reducing risk of injuries [28]. It is well documented that large muscle mass is associated with good health regardless of BMI [29]. Strength training $2 \times 10$ min weekly was not enough to increase muscle mass, but on the other hand, participants maintained their muscle mass, despite a weight reduction, which may be a result of supervised training sessions that included resistance training. Further, there was a significant interaction effect (Time $\mathrm{x}$ Group) for visceral fat, which indicates a significant decrease in visceral fat for the NTG from T1 to T3 $(\mathrm{p}<0.05)$ and an increase for TG (non-significant). Different weight 
loss regimens might lead to different distribution of visceral fat [19]. A good indicator of having a high level of visceral fat is a high BMI and a large WC [22]. Despite a reduction in WC, the TG showed a possible increase in visceral fat. Training might have reduced their WC, but if the consumption of saturated fat was high, this might have led to a possible increased level of visceral fat. Exercise training might also direct energy storage to depots other than the viscera [17]. According to Verheggen et al. [45], reduction in visceral fat also results in great health benefits.

\section{Limitations of the study}

Although this research was carefully planned, there are some limitations and shortcomings. One limitation is that the study has no control group. And because of the resources available, for instance, access to a kitchen, this research was only conducted on a small group of people. To generalize the results for a larger group the study should have included more participants. Several participants forgot to return their training diary regularly, and this might have led to an imprecise estimation of exercise when finally filling it out. We had no control over participants' diet and participants in the TG may have focused on improving their diet, even if they were told to eat the same as they normally did when entering the project. Participants in the NTG were recommended to reduce their calorie intake, but their food intake was not supervised.

\section{Conclusions}

Untrained, inactive and overweight adults who started with two weekly intensive running sessions increased their aerobic capacity and significantly reduced their BMI, WC and fat percentage during 33 weeks of training. A strong negative relationship between $\mathrm{VO}_{2 \max }$ and running time was found. Both groups improved their running time and anthropometric measurements. Giving lifestyle modification education and cooking lessons in addition to the supervised training, resulted in only small additional changes.

\section{ACKNOWLEDGEMENTS}

Rogaland County Council (food costs) and the University of Stavanger funded the study. The newspaper Stavanger Aftenblad gave the study advance publicity and was helpful in recruiting readers to the study. Forus Helse, represented by Merete Ree Frafjord, was medically responsible for the participants. The authors declare no conflicts of interest. Data may be available on request. 


\section{REFERENCES}

1. Blair SN, Archer E, Hand GA. (2013) Commentary: Luke and Cooper are wrong: physical activity has a cruical role in weight management and determinants of obesity. Int J Epidemiol, 42: 1836-1838.

2. Blair SN, Brodney, S. (1999) Effects of physical inactivity and obesity on morbidity and mortality: current evidence and research issues. Med Sci Sports Exerc, 31: 646-662.

3. Blair SN, LaMonte MJ. (2006) Commentary: Current perspectives on obesity and health: black and white, or shades of grey? Int J Epidemiol, 35: 69-72.

4. Borg G. (1998). Borg's perceived exertion and pain scales. Human Kinetics, Champaign, IL, US.

5. Clark JE. (2015) Diet, exercise or diet with exercise: comparing the effectiveness of treatment options for weight-loss and changes in fitness for adults (18-65 years old) who are overfat, or obese; systematic review and meta-analysis. J Diabetes Metab Disord, 14: 31.

6. Cohen J. (1988) Statistical power analysis for the behavioral sciences. Department of Pschology, New York University, New York: Lawrence Erlbaum Associates Publishers, sec ed.

7. Edvardsen E, Hem E, Anderssen, SA. (2014) End Criteria for Reaching Maximal Oxygen Uptake Must Be Strict and Adjusted to Sex and Age: A Cross-Sectional Study. PLoS One, 9: e85276.

8. Ekelund U, Ward HA, Norat T, Luan J, May AM, Weiderpass E, J Sharp SJ, Overvad K, Nautrup Østergaard J, Tjønneland A. (2015) Physical activity and all-cause mortality across levels of overall and abdominal adiposity in European men and women: the European Prospective Investigation into Cancer and Nutrition Study (EPIC). Am J Clin Nutr, 101: 613-621.

9. Fayh AP, Lopes AL, da Silva AM, Reischak-Oliveira A, Friedman R. (2013) Effects of $5 \%$ weight loss through diet or diet plus exercise on cardiovascular parameters of obese: a randomized clinical trial. Eur J Nutr, 52: 1443-1450.

10. Freedman DS, Ford ES. (2015) Are the recent secular increases in the waist circumference of adults independent of changes in BMI? Am J Clin Nutr, 101: 425.

11. Hankinson AL, Daviglus ML, Bouchard C, Carnethon M, Lewis CE, Schreiner PJ, Liu KA, Sidney S. (2010) Maintaining a High Physical Activity Level Over 20 Years and Weight Gain. JAMA, 304: 2603-2610.

12. Hansen BH, Holme I, Anderssen SA, Kolle E. (2013) Patterns of objectively measured physical activity in normal weight, overweight, and obese individuals (20-85 years): a cross-sectional study. PLoS One, 8: e53044.

13. Harvey SB, Øverland S, Hatch SL,Wessely S, Mykletun A, Hotopf M. (2017) Exercise and the prevention of depression: Results of the HUNT cohort study. Am J Psychiatry: appi. ajp. 2017.16111223.

14. Helsedirektoratet (Norwegian Directorate of Health). (2005). Norske anbefalinger for ernæring og fysisk aktivitet. 
15. Helsedirektoratet (Norwegian Directorate of Health). (2011) Kostråd for å fremme og forebygge kroniske sykdommer. In, edited by Helsedirektoratet. Norway.

16. Helsedirektoratet (Norwegian Directorateof Health) (2014) Fysisk aktivitetsnivå blant voksne og eldre i Norge. Oppdaterte analyser basert på nye nasjonale anbefalinger i 2014.

17. Hunter GR, Brock DW, Byrne NM, Chandler-Laney PC, Del Corral P, Gower BA. (2010) Exercise training prevents regain of visceral fat for 1 year following weight loss. Obesity, 18: 690-695.

18. Huxley RS, Zheleznyakov ME, Reddy S, Chan J. (2009) Body mass index, waist circumference and waist:hip ratio as predictors of cardiovascular risk - a review of the literature. Eur J Clin Nutr, 64: 16.

19. Idoate, FJ, Ibañez E, Gorostiaga M, García-Unciti M, Martínez-Labari C, Izquierdo M. (2011) Weight-loss diet alone or combined with resistance training induces different regional visceral fat changes in obese women.Int Journ of Obes, 35: 700-713

20. Jacobsen BK, Aars NA. (2016) Changes in waist circumference and the prevalence of abdominal obesity during 1994-2008-cross-sectional and longitudinal results from two surveys: the Tromsø study. BMC Obesity, 3: 41.

21. Jane M, Hagger M, Foster J, Ho S, Kane R, Pal S. (2017) Effects of a weight management program delivered by social media on weight and metabolic syndrome risk factors in overweight and obese adults: A randomised controlled trial. PLoS One, 12: e0178326.

22. Janssen IS, Heymsfield B, Allison DB, Kotler DP, Ross R. (2002) Body mass index and waist circumference independently contribute to the prediction of nonabdominal, abdominal subcutaneous, and visceral fat. Am J Clin Nutr, 75 : 683-688.

23. Janssen IP, Katzmarzyk T, Ross R. (2004) Waist circumference and not body mass index explains obesity-related health risk. Am J Clin Nutr, 79: 379-384.

24. Jenum, AK, Graff-Iversen S, Selmer R, Søgård AJ. (2007). Risk factors for cardiovascular disease and diabetes through decades. Tids Nor L, 127: 2532-2536.

25. King, NA, Hopkins M, Caudwell P, Stubbs RJ, Blundell JE. (2009) Beneficial effects of exercise: shifting the focus from body weight to other markers of health. Br J Sports Med, 43: 924-927.

26. Klem ML. (2000) Successful losers. The habits of individuals who have maintained long-term weight loss. Minnesota Medicine, 83: 43-45.

27. Kodama S, Saito K, Tanaka S, Maki M, Yachi Y, Asumi M, Sugawara A, Totsuka K, Shimano H, Ohashi Y, Yamada N, Sone H. (2009) Cardiorespiratory Fitness as a Quantitative Predictor of All-Cause Mortality and Cardiovascular Events in Healthy Men and Women A Meta-analysis. JAMA, 301: 2024-2035.

28. Lauersen, JB, Bertelsen DM, Andersen LB. (2014) The effectiveness of exercise interventions to prevent sports injuries: a systematic review and meta-analysis of randomised controlled trials. Br J Sports Med, 48: 871-787. 
29. Lavie CJ, De Schutter A, Milani RV. (2015) Healthy obese versus unhealthy lean: the obesity paradox. Nat Rev Endocrin, 11: 55.

30. Lean MEJ, Han TS, Morrison CE. (1995) Waist circumference as a measure for indicating need for weight management. BMJ, 311: 158-161.

31. Leitzmann MF, Park Y, Blair A, Ballard-Barbash R, Mouw T, Hollenbeck AR, Schatzkin A. (2007) Physical activity recommendations and decreased risk of mortality. Arch Intern Med, 167: 2453-2460.

32. Luke A, Cooper R. (2013) Physical activity does not influence obesity risk: time to clarify the public health message. Int J Epidemiol, 42: 1831-36.

33. Lv N, Azar KMJ, Goldman Rosas L, Wulfovich S, Xiao L, Ma J. (2017) Behavioral lifestyle interventions for moderate and severe obesity: A systematic review. Prev Med, 100: 180-193.

34. Manson JE, Greenland P, LaCroix AZ, Stefanick ML, Mouton CP, Oberman A, Perri MG, Sheps DS, Pettinger MB, Siscovick. DS. (2002) Walking compared with vigorous exercise for the prevention of cardiovascular events in women. $\mathrm{N}$ Engl J Med, 347: 716-725.

35. Martinez-Gonzalez MA, Martinez JA, Hu FB, Gibney MJ, Kearney J. (1999) Physical inactivity, sedentary lifestyle and obesity in the European Union. Inte J Obes, 23: 1192-1201.

36. Midthjell KLCMY, Lee CMY, Langhammer A, Krokstad S, Holmen TL, Hveem K, Colagiuri S, Holmen J. (2013) Trends in overweight and obesity over 22 years in a large adult population: the HUNT Study, Norway. Clin Obes, 3: 12-20.

37. Oja P, Bull FC, Fogelholm M, Martin BW. (2010) Physical activity recommendations for health: what should Europe do? BMC Public Health, 10: 1-5.

38. Pedersen BK, Saltin B. (2015) Exercise as medicine-evidence for prescribing exercise as therapy in 26 different chronic diseases. Scand J Med Sci Sports, 25: $1-72$.

39. Pescatello LS, Arena R, Riebe D, Thompson PD. (2014) ACSM's guidelines for exercise testing and prescription. Wolters Kluwer Health/Lippincott Williams \& Wilkins: Philadelphia.

40. Piirtola M, Kaprio J, Waller K, Heikkila K, Koskenvuo M, Svedberg P, Silventoinen K, Kujala UM, Ropponen A. (2017) Leisure-time physical inactivity and association with body mass index: a Finnish Twin Study with a 35-year followup. Int J Epidemiol, 46: 116-127.

41. Reiner M, Niermann C, Jekauc D, Alexander Woll A. (2013) Long-term health benefits of physical activity - a systematic review of longitudinal studies. BMC Public Health, 13: 1-9.

42. Samitz G, Egger M, Zwahlen M. (2011) Domains of physical activity and allcause mortality: systematic review and dose-response meta-analysis of cohort studies. Inte J Epidemol, 40: 1382-1400.

43. Taghizadeh N, Boezen HM, Schouten JP, Schröder CP, de Vries EGE, Vonk JM. (2015) BMI and Lifetime Changes in BMI and Cancer Mortality Risk. PLoS One, 10. 
44. Torre LA, Bray A, Siegel RL, Ferlay J, Lortet-Tieulent J, Jemal A. (2015) Global cancer statistics, 2012. CA: a cancer journal for clinicians, 65: 87-108.

45. Verheggen RJHM, Maessen MFH, Green DJ,Hermus ARMM, Hopman MTE, Thijssen DHT. (2016) A systematic review and meta-analysis on the effects of exercise training versus hypocaloric diet: distinct effects on body weight and visceral adipose tissue. Obes Rev, 17: 664-690.

46. Verma, JP (2015) Repeated Measures Design for Empirical Researchers.John Wiley \& Sons, Incorporated: New Jersey.

47. Vuori I. (2010) Physical activity and cardiovascular disease prevention in Europe: an update, Kinesiology, 42: 5-15.

48. Warburton DE, Charlesworth S, Ivey A, Nettlefold L, Sd Bredin S. (2010) A systematic review of the evidence for Canada's Physical Activity Guidelines for Adults. IJBNPA, 7: 39-39.

49. Weiss EP, Jordan RC, Frese EM, Albert SG, Villareal DT. (2017) Effects of Weight Loss on Lean Mass, Strength, Bone, and Aerobic Capacity. Med Science Sports Exerc, 49: 206-217.

50. Wewege M, Berg R, Ward RE, Keech A. (2017) The effects of high-intensity interval training vs. moderate-intensity continuous training on body composition in overweight and obese adults: a systematic review and meta-analysis. Obes Revs, 18: 635-346.

51. World Health Organization (2000) Obesity: preventing and managing the global epidemic: report of a WHO consultation.” In, edited by WHO, 252. WHO: Geneva.

52. World Health Organization, Division of Noncommunicable, Diseases, Health Mental, and WHO. Consultation on Obesity (1998). Obesity : preventing and managing the global epidemic: report of a WHO consultation on obesity, Geneva, 3-5 June 1997. In. Geneva: WHO.

53. World Health Organization (2000. The Asia-Pacific perspective. Redefining obesity and its treatment. International Association for the Study of Obesity. International Obesity Task Force. Western Pacific Region.

\section{Correspondence to:}

Leif Inge Tjelta

Department of Education and Sports Science,

University of Stavanger,

Norway

E-mail: leif.i.tjelta@uis.no 